\title{
Paneth Cell Hyperplasia and Metaplasia in Necrotizing Enterocolitis
}

\author{
PATRYCJA J. PUIMAN, NANDA BURGER-VAN PAASSEN, MAAIKE W. SCHAART, ADRIANUS C.J.M. DE BRUIJN, \\ RONALD R. DE KRIJGER, DICK TIBBOEL, JOHANNES B. VAN GOUDOEVER, AND INGRID B. RENES
}

\author{
Department of Neonatology [P.J.P., N.B.-P., M.W.S., A.C.J.M.B., J.B.G., I.B.R.], Department of Pediatric Surgery [M.W.S., D.T.], \\ Erasmus MC-Sophia Children's Hospital, Rotterdam 3015 GJ, The Netherlands; Department of Pathology [R.R.K.], Erasmus \\ MC-Josephine Nefkens Institute, Rotterdam 3015 GJ, The Netherlands
}

\begin{abstract}
Paneth cell dysfunction has been suggested in necrotizing enterocolitis (NEC). The aim of this study was to i) study Paneth cell presence, protein expression, and developmental changes in preterm infants with NEC and ii) determine Paneth cell products and antimicrobial capacity in ileostomy outflow fluid. Intestinal tissue from NEC patients $(n=55)$, preterm control infants $(n=22)$, and term controls $(n=7)$ was obtained during surgical resection and at stoma closure after recovery. Paneth cell abundance and protein expression were analyzed by immunohistochemistry. RNA levels of Paneth cell proteins were determined by real-time quantitative RTPCR. In ileostomy outflow fluid, Paneth cell products were quantified, and antimicrobial activity was measured in vitro. In acute NEC, Paneth cell abundance in small intestinal tissue was not significantly different from preterm controls. After recovery from NEC, Paneth cell hyperplasia was observed in the small intestine concomitant with elevated human alpha-defensin 5 mRNA levels. In the colon, metaplastic Paneth cells were observed. Ileostomy fluid contained Paneth cell proteins and inhibited bacterial growth. In conjunction, these data suggest an important role of Paneth cells and their products in various phases of NEC. (Pediatr Res 69: 217-223, 2011)
\end{abstract}

$\mathrm{P}$ aneth cells, named after Joseph Paneth (1), play a significant role in the innate immune response. Localized at the base of the crypts of Lieberkühn, Paneth cells are abundant in the ileum and are only occasionally found in the proximal colon (2). Paneth cells have defensive functions including 1) protection of stem cells in response to invading microbes $(3,4) ; 2)$ eradication of ingested pathogens $(5-7) ; 3)$ regulation of the composition, distribution, and number of commensal bacteria in the intestinal lumen $(8,9)$; and 4 ) induction of cytokine secretion, immune cell recruitment, and chloride secretion to flush the intestinal crypts of pathogens $(10,11)$.

Paneth cells execute their functions by production of antimicrobial proteins/peptides such as lysozyme $(12,13)$, secretory phospholipase-A2 (sPLA2) (14), and human $\alpha$-defensins (HD5 and -6) $(15,16)$. In the human fetal intestine, Paneth cells are present from 20 wk of gestation; however, HD5 and -6 mRNAs are expressed from 13.5 wk onward $(17,18)$. Both Paneth cell numbers and HD5 and -6 mRNA expression are lower in premature infants at $24 \mathrm{wk}$ of gestation compared

Received June 8, 2010; accepted October 14, 2010.

Correspondence: Ingrid B. Renes, Ph.D., Erasmus MC, Lab Pediatrics, Rmnr. Ee 1575A, Dr. Molewaterplein 50, Rotterdam 3015 GE, The Netherlands; e-mail: i.renes@erasmusmc.nl

Supported, in part, by Danone. with term infants, and up to 200-fold lower than in adults (18). In the premature infant, who is often exposed to nosocomial pathogens and has delayed colonization with beneficial commensals, this phenomenon could result in higher susceptibility to bacterial infection and inflammation.

Although Paneth cell dysfunction in necrotizing enterocolitis (NEC) has been suggested (19), little is known about Paneth cell abundance and function in preterm infants at risk for NEC. NEC is the most common gastrointestinal disease in premature infants with mortality rates up to $50 \%$ for infants needing surgery $(20,21)$. Risk factors for NEC are prematurity, very low birth weight, enteral formula feeding, and bacterial colonization (22-24). However, the underlying etiology and the impact of the innate immune system on the development of NEC require further investigation.

We hypothesized that preterm infants with acute NEC have fewer Paneth cells compared with control patients, and that Paneth cell numbers are up-regulated during recovery from NEC, thereby enhancing the innate immune response. Our aim was i) to study Paneth cell presence, Paneth cell protein expression, and disease-related changes in Paneth cell numbers over time in premature infants with NEC compared with control patients and ii) to measure Paneth cell products in ileostomy outflow fluid during NEC recovery and to determine the bactericidal activity of ileal outflow fluid.

\section{METHODS}

Study population. Premature infants who underwent bowel resection for NEC between August 2003 and September 2009 were eligible for the study. NEC was diagnosed and staged according to the criteria of Bell et al. (25). Diagnosis was confirmed during surgery and by histopathological evaluation of resected intestinal tissue. Samples of both ends of the resected intestine represented macroscopically vital tissue and were collected for histology and real-time quantitative RT-PCR (real time qRT-PCR).

Approximately 3-5 wk after surgery, when infants received an enteral intake of at least $100 \mathrm{~mL} \cdot \mathrm{kg} \cdot \mathrm{d}$, enterostomy outflow fluid was collected

\footnotetext{
Abbreviations: A-NEC, acute phase of necrotizing enterocolitis; CFU, colony forming units; HD, human defensins; LGG, Lactobacillus rhamnosus GG; NEC, necrotizing enterocolitis; NEC-R, stoma reanastomosis after necrotizing enterocolitis; post-NEC stricture, stricture formation after acute phase of necrotizing enterocolitis; preterm CO, preterm control patients; preterm CO-R, stoma reanastomosis in preterm control patient; qRT-PCR, real-time quantitative PCR; sPLA2, secretory phospholipase-A2; term CO, term control patient
} 
every $3 \mathrm{~h}$ for $24 \mathrm{~h}$ and immediately stored at $-20^{\circ} \mathrm{C}$. After full recovery, patients underwent a second surgical procedure when eligible for reanastomosis (i.e. stoma closure). To allow proper reanastomosis, tissue was resected, which was collected for histology.

Patients who underwent surgery for resection of post-NEC strictures, as a result of obstructive fibrotic intestinal tissue that developed during nonsurgical therapy for NEC, were also included. These samples were not subjected to surgical manipulation or exposed to the extra-abdominal environment and are thus representative for the effects of NEC only. Moreover, samples were taken from both the proximal and distal part of the resected intestine.

Finally, both preterm and term neonates who underwent resection for developmental defects or diseases other than NEC were included as control patients, and intestinal tissue was collected as described earlier. Infants diagnosed with cystic fibrosis were excluded. The study protocol was approved by the "Central Committee on Research involving Human Subjects" (The Hague, the Netherlands), and written informed consent was obtained from the parents.

Histology and immunohistochemistry. Intestinal tissues were fixed in $4 \%$ (wt/vol) paraformaldehyde in PBS for $24 \mathrm{~h}$ at $4{ }^{\circ} \mathrm{C}$ and processed for light microscopy. Five micrometer-thick sections were cut and deparaffinized through a graded series of xylol-ethanol. For histology, tissue samples were stained with hematoxylin and eosin. To determine Paneth cell-specific expression of lysozyme, trypsin, and HD5, immunohistochemistry was performed as described previously $(26,27)$. Antibodies used were anti-human lysozyme (Dako, Glostrup, Denmark), anti-human trypsin (MAB 1482; Millipore, Billerica, MA), and anti-human HD5 (HyCult Biotechnology, Uden, the Netherlands). Secondary antibodies applied were biotinylated horse antimouse IgG diluted (Vector Laboratories, Burlingame, England) and biotinylated goat anti-rabbit IgG (Vector Laboratories). Detection was performed using the ABC-PO complex (Vectastain Elite Kit, Vector Laboratories). Staining was developed using diaminobenzidine.

Collected tissue samples were assigned to intestinal segments according to their origin: jejunum, ileum, coecum, colon ascendens, colon transversum, colon descendens, and rectosigmoid. When samples originated from the same intestinal segment, only one sample per segment was analyzed. Samples from NEC and control infants were matched and analyzed according to their segment of origin. Tissue morphology was qualitatively assessed by two trained observers (P.J.P. and I.B.R.). A semi-quantitative assessment of Paneth cell abundance based on lysozyme and HD5 positive cells was performed. Paneth cells within 10 crypts per tissue sample were scored blinded as follows: 0, no Paneth cells; $1,0-1$ Paneth cells per crypt and at least 1 Paneth cell per 10 crypts; 2, 1-4 Paneth cells per crypt; and 3, >4 Paneth cells per crypt. Scores were given by one observer and validated by the second observer.

Real-time Quantitative RT-PCR. RNA was isolated from snap-frozen ileal tissue (RNeasy Midi kit; Qiagen Benelux, Venlo, the Netherlands) and used for cDNA synthesis. Expression levels of DEFA5 (HD5), LYZ (lysozyme), TRY2 (anionic trypsin), and PLA2G2A (sPLA2) were quantified using qRTPCR analysis based on the intercalation of SYBR Green on an ABI prism 7900HT Fast real-time PCR system (PE Applied Biosystems, Foster City, CA) as described previously (28). The mRNA levels were expressed relative to the epithelial-specific housekeeping gene VIL1 (Villin). Primer combinations are given in Table 1.

Protein isolation and Western blot analyses. To isolate proteins from the small intestinal outflow fluid, cesium-chloride density gradient ultracentrifugation was performed as described previously $(29,30)$. Fractions with a buoyant density $>1.35 \mathrm{~g} / \mathrm{mL}$, containing high-density proteins, were discarded. Fractions with a buoyant density $<1.35 \mathrm{~g} / \mathrm{mL}$ were pooled, dialyzed, and used to quantify lysozyme, trypsin, and sPLA2 by Western blot. The used dialysis membrane had a cut-off size of $10 \mathrm{kD}$ and therefore did not allow analysis of HD5 as HD5 is smaller than $10 \mathrm{kD}$. Primary antibodies used were rabbit anti-lysozyme (Dako), rabbit anti-sPLA2 (H-74; Santa Cruz Biotechnology, Santa Cruz, CA), and mouse anti- $\alpha$-trypsin (MAB 1482; Chemicon International). Bound antibodies were detected using HRP-conjugated goat anti-rabbit or anti-mouse antibodies and Luminol Enhancer (Pierce, Thermo Fisher Scientific, Inc., Rockford, IL). Western blots were analyzed using densitometry.

Antimicrobial assay. Escherichia coli (E. coli), Lactococcus lactis ( $L$. lactis), and Lactobacillus rhamnosus ( $L G G$ ) were grown overnight in LB medium, GM17 medium, and MRS medium (BD, Franklin Lakes, NJ), respectively, at $37^{\circ} \mathrm{C}$. The pooled antimicrobial protein fractions $(100 \mu \mathrm{g})$ were added to $200 \mu \mathrm{L}$ of bacterial cultures of $2 \times 10^{7}$ colony forming units (CFUs) $/ \mathrm{mL}$ and incubated for $1 \mathrm{~h}$ at $37^{\circ} \mathrm{C}$. A $10^{-4}$ dilution was prepared, and $100 \mu \mathrm{L}$ of the suspension was plated. After overnight incubation at $37^{\circ} \mathrm{C}$, CFUs were counted. Bacterial growth inhibition was analyzed by calculating the number of CFUs in comparison with untreated bacteria.

Statistical analysis. Comparisons between patient groups were made using ANOVA with a post hoc Tukey $t$ test for normally distributed data or the Kruskal-Wallis test followed by Dunn's Multiple Comparison test for notnormally distributed data. Protein and mRNA levels of antimicrobial proteins were determined using the Mann Whitney test. Analyses were performed using GraphPad Prism version 5.0 (GraphPad Software, San Diego, CA). Significance was defined at $p<0.05$.

\section{RESULTS}

Study population. A total of 84 infants were included in the study. Patient characteristics are shown in Table 2. Forty-nine preterm infants underwent bowel resection for stage III acute NEC, further referred to as A-NEC. After resection of necrotic tissue, primary anastomosis was performed in four patients and an enterostomy was created in 40 infants; in five patients, NEC lesions were too extensive to allow further surgical treatment compatible with life. In total, 13 infants (27\%) died of complications of NEC. After recovery, 31 of the 40 enterostomy patients were eligible for reanastomosis (further referred to as NEC-R), allowing repeated tissue collection. In addition, six premature infants were included, who had received nonsurgical treatment for NEC but developed postNEC strictures requiring surgery (post-NEC stricture).

Twenty-two premature infants were included as control (preterm CO). These patients were diagnosed with small intestinal atresia $(n=8)$, milk curd obstruction $(n=3)$, perforation caused by herniation $(n=2)$, solitary perforation $(n=1)$, ileus $(n=1)$, Meckel's diverticulum $(n=1)$, volvulus $(n=2)$, gastroschizis $(n=3)$, and cloacal malformation $(n=1)$. After intestinal resection, six infants received a primary anastomosis and 16 received an enterostomy. Postsurgically, one patient died of additional clinical complications. After full recovery, 13 infants were eligible for stoma closure (preterm CO-R), allowing repeated tissue collection. Seven term infants who were resected for small intestinal atresia $(n=3)$, intestinal perforation $(n=3)$, and volvulus $(n=1)$ were included as term controls (Term CO). Figure 1 depicts the corrected GA at the time of tissue sampling during surgery for all patient groups.

Table 1. Primer sequences used for real-time $q R T-P C R$

\begin{tabular}{|c|c|c|}
\hline Gene & Forward primer & Reverse primer \\
\hline$L Y Z$ & 5'- TTT GCT GCA AGA TAA CAT C -3' & 5'- GAC GGA CAT CTC TGT TTT G -3' \\
\hline DEFA5 & $5^{\prime}-$ TGC AGG AAA TGG ACT CTC $-3^{\prime}$ & $5^{\prime}-$ GCC ACT GAT TTC ACA CAC - $3^{\prime}$ \\
\hline$P L A 2 G 2 A$ & 5'- TGG CAC CAA ATT TCT GA -3' & $5^{\prime}-$ GCA GCC TTA TCA CAC TCA $-3^{\prime}$ \\
\hline$T R Y 2$ & $5^{\prime}-$ GCT CCA AGG AAT TGT CTC $-3^{\prime}$ & 5'- GGG GCT TTA GCT GTT G -3' \\
\hline VILI & 5'- CTG CCT TCT CTG CTC TG -3' & $5^{\prime}-$ ATC GGT GAG AAA ATG AGA C -3' \\
\hline
\end{tabular}

Primers for DEFA5 (HD5), LYZ (lysozyme), TRY2 (anionic trypsin), and PLA2G2A (secretory phospholipase A2) were designed using OLIGO 6.22 software (Molecular Biology Insights, Cascade, CO). 
Table 2. Patient demographics

\begin{tabular}{|c|c|c|c|c|c|}
\hline & NEC & Post-NEC stricture & Preterm CO & Term CO & $p$ \\
\hline No. patients & 49 & 6 & 22 & 7 & \\
\hline \multicolumn{6}{|l|}{ Demographics } \\
\hline Sex, \% male & 61 & 67 & 50 & 57 & \\
\hline GA (wk) & $29.5 \pm 3$ & $31.8 \pm 3.7$ & $32.9 \pm 3.9$ & $38.2 \pm 1.2$ & $a, c, i, k$ \\
\hline Birth weight (g) & $1239 \pm 501.8$ & $1618 \pm 507.5$ & $2051 \pm 874.8$ & $2946 \pm 738.9 *$ & $a, c, h, j$ \\
\hline Apgar score $1 \mathrm{~min}$ & $7(4-9)$ & $7.5(2.9-9)$ & $8(5-9) *$ & $9(8-9) \dagger$ & NS \\
\hline Apgar score 5 min & $9(8-10)$ & $9.5(8.3-10)$ & $9(8-9)^{*}$ & $9(9-10) \dagger$ & NS \\
\hline \multicolumn{6}{|l|}{ Clinical and surgical outcome } \\
\hline Postnatal age at 1 st surgery (d) & $11(7-17.5)$ & $40(35.8-51)$ & $1.5(0-16)$ & $2(0-3)$ & $b, d, e, g, h$ \\
\hline GA at 1st surgery (wk) & $31.7(29.2-34)$ & $38(35.8-40.5)$ & $34.4(31-36.1)$ & $38(37.6-40.3)$ & $b, c, f$ \\
\hline Primary anastomosis $(\%)$ & 8 & 100 & 27 & 42.3 & \\
\hline Jejunostomy (\%) & 12 & - & 23 & 14.3 & \\
\hline Ileostomy $(\%)$ & 61 & - & 45 & 42.3 & \\
\hline Colostomy $(\%)$ & 8 & - & 4 & - & \\
\hline Deaths $(\%)$ & 27 & - & 4 & - & \\
\hline Patients eligible for reanastomosis $(\%)$ & 63 & - & 59 & - & \\
\hline Postnatal age at reanastomosis (d) & $95(57-125)$ & - & $55(44-102)$ & - & NS \\
\hline GA at reanastomosis (wk) & $43(40.1-46.6)$ & - & $41(39.5-46.4)$ & - & NS \\
\hline
\end{tabular}

Data provided are percentages or means \pm SD. Medians (interquartile range) are provided for variables that are not normally distributed.

* Data on one patient were not recorded.

$\dagger$ Data on two patients were not recorded.

${ }^{a} p<0.001$ for comparisons between NEC and preterm controls.

${ }^{b} p<0.05$ for comparisons between NEC and preterm controls.

${ }^{c} p<0.001$ for comparisons between NEC and term controls.

${ }^{d} p<0.05$ for comparisons between NEC and term controls.

${ }^{e} p<0.05$ for comparisons between NEC and post-NEC strictures.

${ }^{f} p<0.001$ for comparisons between NEC and post-NEC strictures.

${ }^{j} p<0.001$ for comparisons between post-NEC strictures and preterm controls.

${ }^{h} p<0.001$ for comparisons between post-NEC strictures and term controls.

${ }^{i} p<0.01$ for comparisons between post-NEC strictures and term controls.

${ }^{j} p<0.05$ for comparisons between preterm controls and term controls.

${ }^{k} p<0.01$ for comparisons between preterm controls and term controls.

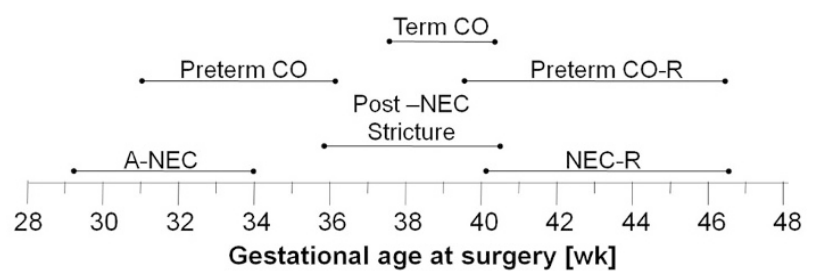

Figure 1. Time frame representing an overview of intestinal tissue sampling according to GA. Bars represent interquartile ranges. A-NEC patients are significantly younger than preterm CO (Mann-Whitney $p<0.01$ ), but corrected GA is comparable during reanastomosis. Corrected GA during reanastomosis is in both groups not different from patients with post-NEC strictures and term controls during surgery.

Sample evaluation. In most infants, the resected intestine covered multiple intestinal segments. Samples were cut from both ends of the resected material and therefore sample numbers do not correlate with the number of patients included. Samples from jejunum, ileum, and colon were used for morphological analysis $(n=157)$. Samples that showed complete mucosal erosion were excluded from further analyses $(n=$ 36). The remaining samples were stained for lysozyme, HD5, and trypsin to analyze Paneth cell-specific protein expression. Scoring was based on both lysozyme and HD5 staining. Table 3 demonstrates the number of samples that were obtained and evaluated for each patient group.

Paneth cell hyperplasia during NEC recovery. Paneth cells were present in small intestinal tissue of NEC patients and
Table 3. Sample evaluation of intestinal tissue obtained during acute surgery and reanastomosis

\begin{tabular}{|c|c|c|c|c|c|c|}
\hline & \multicolumn{6}{|c|}{ Patient groups } \\
\hline & \multicolumn{3}{|c|}{ Small intestine } & \multicolumn{3}{|c|}{ Colon } \\
\hline & Total & Excluded & Evaluated & Total & Excluded & Evaluated \\
\hline \multicolumn{7}{|l|}{ Acute surgery } \\
\hline NEC & 46 & 16 & 30 & 18 & 8 & 10 \\
\hline $\begin{array}{l}\text { Post-NEC } \\
\text { stricture }\end{array}$ & 0 & 0 & 0 & 5 & 0 & 5 \\
\hline Preterm CO & 21 & 4 & 17 & 2 & 1 & 1 \\
\hline Term CO & 7 & 1 & 6 & 1 & 0 & 1 \\
\hline \multicolumn{7}{|l|}{ Reanastomosis } \\
\hline NEC & 29 & 3 & 26 & 13 & 2 & 11 \\
\hline Preterm CO & 12 & 1 & 11 & 3 & 0 & 3 \\
\hline
\end{tabular}

Tissue samples were obtained from both ends of resected intestine and might originate from multiple intestinal segments. Therefore, patient numbers do not correlate with sample numbers.

preterm $\mathrm{CO}$ and were positive for lysozyme (Fig. 2A-D), HD5 (Fig. $2 E-H$ ), and trypsin (not shown). Abundance of Paneth cells, determined by lysozyme and HD5 staining, was not significantly different between A-NEC and preterm CO (Fig. $3)$. In reanastomosis samples, no differences in Paneth cell abundance between NEC-R and preterm CO-R were observed (Fig. 3). However, small intestinal samples in both NEC-R and preterm CO-R showed increased numbers of Paneth cells, determined by lysozyme and HD5 staining, when compared with A-NEC and preterm CO samples, respectively (Fig. 3). 


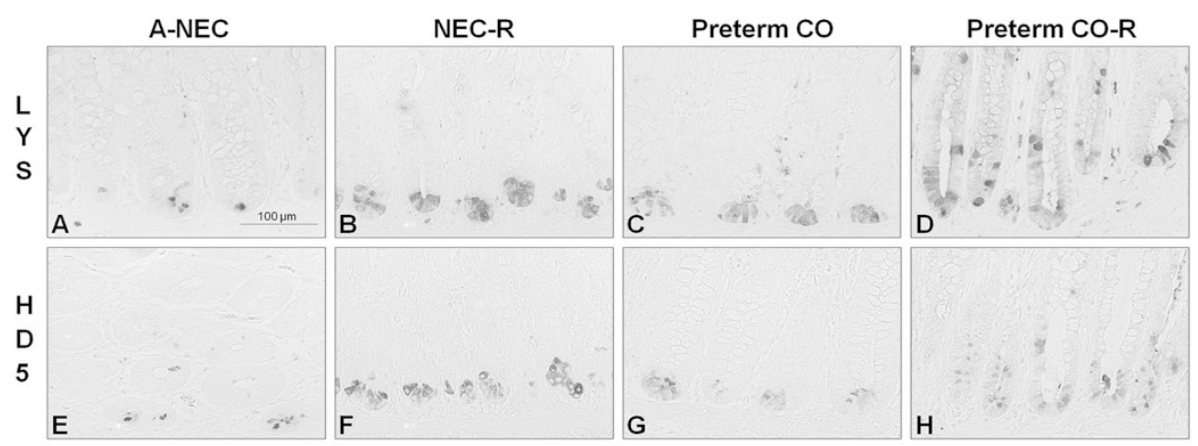

Figure 2. Immunohistochemistry for lysozyme(LYS) $(A-D)$ and HD5-positive $(E-H)$ Paneth cells in ileal tissue from NEC patients and preterm CO. $(A, E)$ A-NEC; $(B, F)$ NEC-R; $(C, G)$ preterm $\mathrm{CO}$; and $(D, H)$ preterm CO-R. Images are representative of 19 A-NEC, 21 NEC-R, nine preterm $\mathrm{CO}$, and six preterm CO-R specimens derived from the ileum.
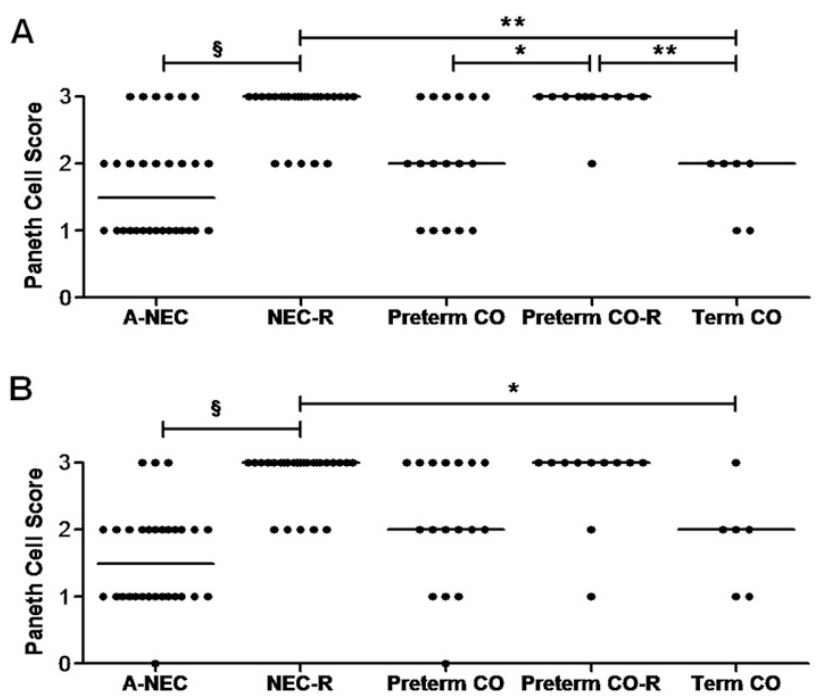

Figure 3. Paneth cell abundance in small intestinal tissue from A-NEC and NEC-R patients, preterm $\mathrm{CO}$ and preterm $\mathrm{CO}-\mathrm{R}$, and term $\mathrm{CO}$ obtained during acute surgery and reanastomosis. Scoring of HD5-positive $(A)$ and lysozyme-positive $(B)$ Paneth cells, based on the number of stained cells per crypt from an average of 10 crypts (see Methods). Lines represent medians. Statistics were performed using the Kruskal-Wallis-Dunn's Multiple Comparison test. ${ }^{*} p<0.05 ; * * p<0.01 ;{ }^{\S} p<0.001$.

To determine whether this increase in Paneth cell numbers was age- or disease-related, we compared term $\mathrm{CO}$ samples with NEC-R and preterm CO-R samples, as the corrected GA at time of surgery was not significantly different between these groups (Fig. 1). Interestingly, Paneth cell abundance in small intestinal NEC-R and preterm CO-R tissue was increased compared with term $\mathrm{CO}$ indicating a disease-related effect.

Paneth cell metaplasia during NEC recovery. In nine of 10 samples, no Paneth cells were found in colonic tissue from A-NEC patients (Figs. 4 and 5). Unexpectedly, at the time of reanastomosis, nearly all proximal and distal colon samples showed metaplastic Paneth cells, determined by lysozyme and HD5 staining (Fig. 4). This finding was confirmed by the post-NEC stricture colon samples, all of which displayed metaplastic Paneth cells (Fig. 4). Figure 5 presents the scoring of Paneth cell abundance in the colon and demonstrates the induction of metaplastic Paneth cells, assessed by staining for HD5 (Fig. 5A) and lysozyme (Fig. 5B), in NEC-R and postNEC stricture. In preterm CO-R, only few colon samples $(n=$ 3) were obtained; however, all samples showed Paneth cell metaplasia (not shown).

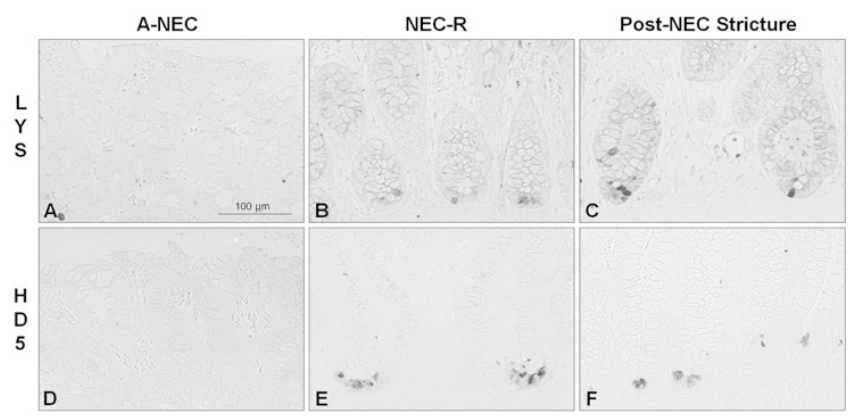

Figure 4. Representative immunohistochemistry for lysozyme (LYS; $A-C$ ) and HD5 $(D-F)$ in metaplastic Paneth cells in colonic tissue from NEC patients. $(A, D) \mathrm{A}-\mathrm{NEC} ;(B, E) \mathrm{NEC}-\mathrm{R}$; and $(C, F)$ post-NEC stricture. Images are representative of $10 \mathrm{~A}-\mathrm{NEC}, 11 \mathrm{NEC}-\mathrm{R}$, and five post-NEC stricture specimens.
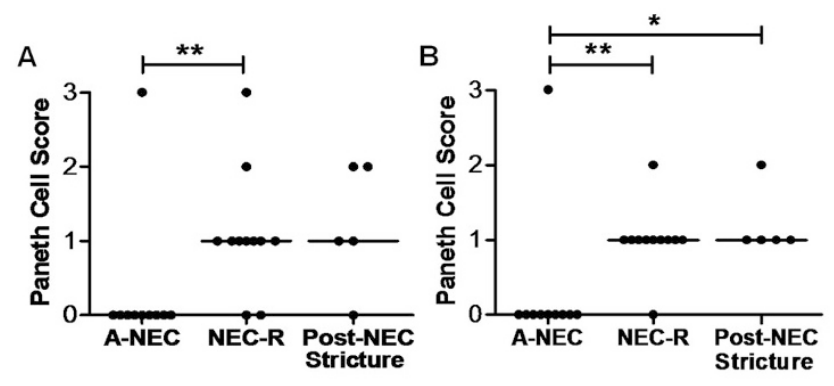

Figure 5. Scoring of Paneth cell abundance in colonic tissue from NEC A-NEC, NEC-R, and post-NEC stricture patients. Scoring of HD5-positive $(A)$ and lysozyme-positive $(B)$ Paneth cells, based on the number of stained cells per crypt from an average of 10 crypts (see Methods). Lines represent medians. Statistics were performed using the Kruskal-Wallis-Dunn's Multiple Comparison test. ${ }^{*} p<0.05$ and ${ }^{*} p p<0.01$.

LYZ, TRY2, PLA2G2A, and DEFA5 gene expression levels in NEC. Analyses of ileal samples from 21 NEC patients by qRT-PCR showed that $L Y Z, T R Y 2$, and PLA2G2A expression levels were not different in tissue from A-NEC $(n=8)$ versus NEC-R ( $n=13$; Fig. 6). However, expression of $D E F A 5$ was significantly higher in NEC-R compared with A-NEC (Fig. 6A-D). Although sample numbers obtained from preterm control infants were limited, expression of $L Y Z$, TRY2, PLA2G2A, and DEFA5 tended to be higher in preterm CO-R samples $(n=5)$ compared with preterm $\mathrm{CO}(n=4$; Fig. $6 E-H)$.

Antimicrobial products in the ileostomy outflow fluid and antimicrobial activity. Ileostomy outflow fluid from 12 patients was collected during the regenerative phase of NEC (Table 4). Isolates of the outflow fluid samples contained 

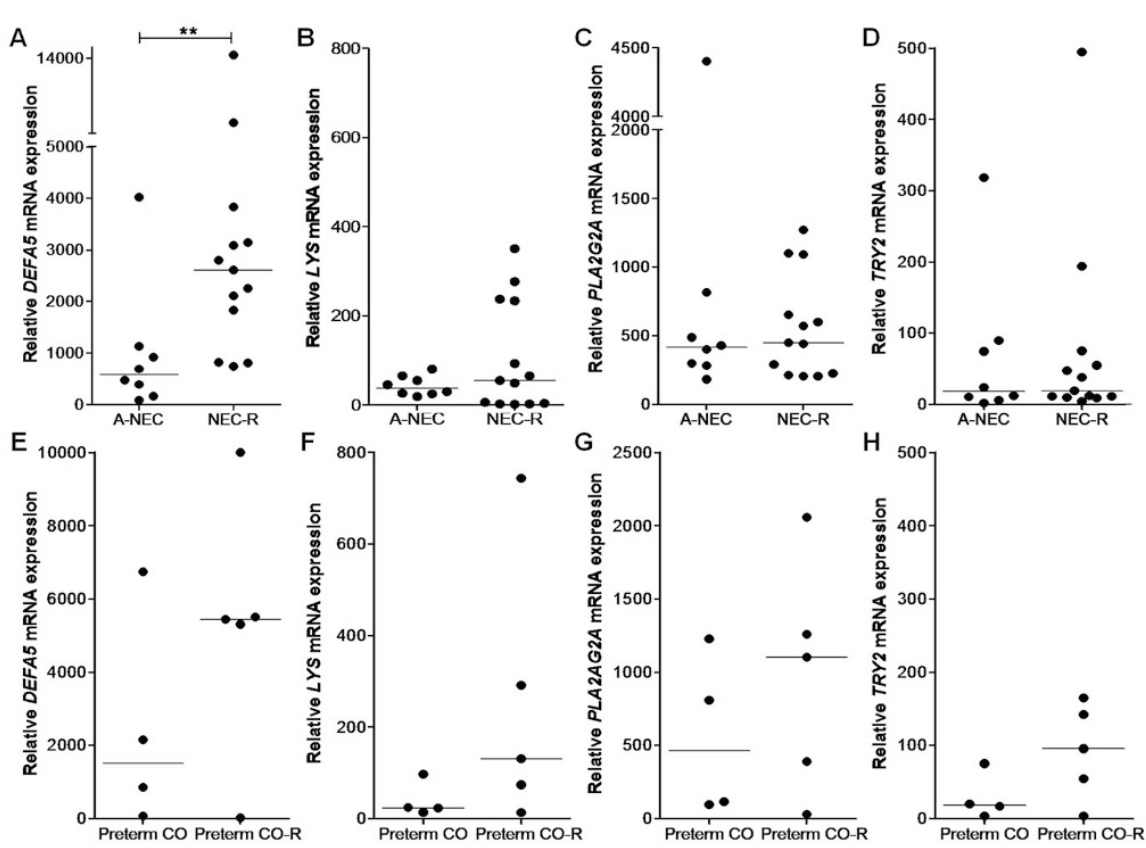

Figure 6. Expression of antibacterial peptide genes in A-NEC and NEC-R $(A-D)$ and preterm $\mathrm{CO}$ and preterm CO-R $(E-H):(A, E)$ DEFA5, $(B, F) L Y S,(C, G) P L A 2 G 2 A$, and $(D, H) T R Y 2$. $D E F A 5$ expression was up-regulated in NEC reanastomosis; Mann Whitney test $p=0.013$. Lines represent medians.

Table 4. Baseline characteristics of NEC patients sampled for ileostomy outflow fluid

$\begin{array}{lc}\text { No. patients } & 12 \\ \text { Demographics } & \\ \text { Sex, \% male } & 92 \\ \text { GA (wk) } & 29.1 \pm 3.1 \\ \text { Birth weight (g) } & 1210 \pm 524 \\ \text { Postnatal age at 1st surgery (d) } & 11.5(7.8-13.5) \\ \text { Time of enterostomy outflow collection } & 22(18.3-25) \\ \quad \text { postsurgery (d) } & 50 \\ \text { Patients receiving breast milk (\%) } & 33 \\ \text { Patients receiving antibiotic treatment during } & \\ \quad \text { sampling (\%) }\end{array}$

Data provided are percentages or means \pm SD. Medians (interquartile range) are provided for variables that are not normally distributed.

lysozyme, trypsin, and sPLA2. Because lysozyme and trypsin are present in breast milk, we analyzed whether levels of these antimicrobial products would differ between infants receiving breast milk $(n=6)$ or formula $(n=6)$. There was no statistically significant difference between the groups (data not shown).

Bactericidal activity of the outflow fluid isolates was demonstrated by growth inhibition of $E$. coli with $52 \%$ ( $\pm 18 \%), L$. lactis with $81 \%( \pm 20 \%$ ), and $L G G$ with $43 \%$ ( $\pm 17 \%$; Fig. $7 A)$. Increasing concentrations of protein isolates $(n=7)$ were used to determine bacterial growth inhibition capacity. Growth inhibition up to $100 \%$ was reached as presented in Fig. $7 B$. To evaluate whether antibiotic treatment influenced the observed effect, we compared bacterial growth inhibition from isolates of antibiotic-treated patients $(n=4)$ with isolates from patients without antibiotics but no difference was observed (Fig. 7).

\section{DISCUSSION}

Paneth cells play a key role in the innate immune response and host defense. Although Paneth cell dysfunction has been
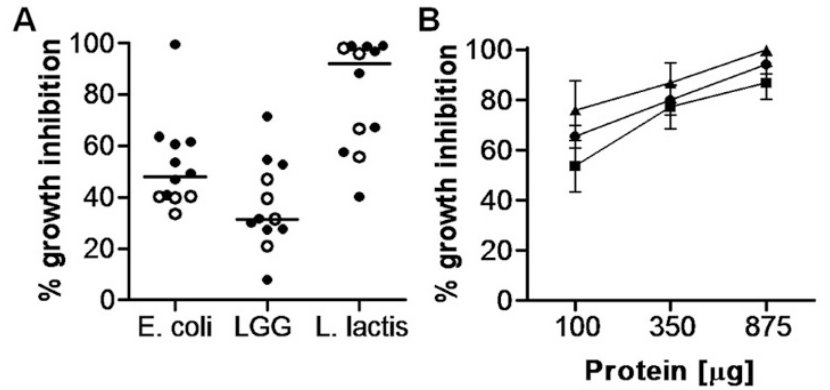

Figure 7. (A) Antimicrobial activity of protein isolates from ileostomy outflow fluid samples $(n=12)$ on E. coli, $L G G$, and L. lactis. Antibacterial activity is expressed as \% growth inhibition compared with nontreated controls. Open symbols denote antibiotic-treated patients. Lines represent means. (B) Antibacterial activity showing up to $100 \%$ growth inhibition of $E$. coli $\diamond, L G G \square$, and L. lactis $\boldsymbol{\Delta}$ with increasing doses of protein isolates $(n=$ 7). Bars represent means \pm SEM.

suggested, little is known about Paneth cell presence and function in the immature gut and gastrointestinal complications of prematurity such as NEC. In this study, we analyzed Paneth cell presence, function, and disease-related changes in Paneth cell abundance over time in preterm infants with NEC. Our results show Paneth cell hyperplasia and metaplasia in premature infants recovering from NEC. Furthermore, Paneth cell products from ileostomy outflow fluid of NEC patients exhibited strong bactericidal activity.

First, Paneth cell presence and protein expression in small intestinal samples of A-NEC patients versus preterm CO were investigated. We found that Paneth cells were present in both A-NEC and preterm CO. Coutinho et al. (19) observed an absence of lysozyme-positive Paneth cells in acute NEC and suggested a developmental defect in Paneth cells, i.e. delayed maturation of Paneth cells, leading to lack of antimicrobial agents such as lysozyme and defensins. Besides the fact that $40 \%$ of their NEC-patients were term newborns in whom the disease is thought to be different from premature infants 
(31-33), the absence of lysozyme-positive Paneth cells might be explained by enhanced secretion of lysozyme. Nevertheless, our study demonstrates Paneth cell-specific lysozyme and HD5 mRNA and protein in A-NEC contradicting Paneth cell deficiency in preterm infants.

Similarly to our results, Salzman et al. (34) showed presence of Paneth cells in acute NEC patients. Semi-quantitative analysis of the six preterm acute NEC infants investigated in that study revealed an increase in Paneth cell numbers and HD5 mRNA levels in infants with NEC compared with (near) term control infants. In our study, we did not observe a difference between A-NEC and term $\mathrm{CO}$ with respect to Paneth cell abundance; however, we did when we compared NEC-R infants to term CO. Another point of interest is that in the study of Salzman et al., intracellular peptide levels in NEC did not coincide with the observed rise in mRNA. Although we did not quantify intracellular peptide levels per Paneth cell, low HD5 mRNA levels coincided with low numbers of HD5positive Paneth cells, whereas high HD5 mRNA levels correlated with the hyperplasia of HD5-positive Paneth cells during reanastomosis. Therefore, our study is the first to report small intestinal Paneth cell hyperplasia after recovery from NEC and strongly implies an up-regulation of Paneth cell abundance. We did not detect differences in lysozyme, sPLA2, and trypsin mRNA levels in A-NEC versus NEC-R. However, in contrast to HD5, these products are not restricted to Paneth cells for their production and therefore do not necessarily reflect changes in Paneth cell abundance.

In concordance to the hyperplasia observed in NEC, Paneth cell numbers in preterm CO-R were also up-regulated compared with preterm CO. Moreover, both preterm CO-R and NEC-R tissue showed higher numbers of Paneth cells compared with term CO. Most likely, severe or prolonged intestinal inflammation, which to a lesser extend was also seen in preterm control infants, might explain the observed hyperplasia. However, the effect of increased postnatal age in this preterm population compared with term $\mathrm{CO}$ cannot be excluded.

A novel finding in our study is the occurrence of Paneth cell metaplasia in colon samples during NEC-recovery. The expression of lysozyme, trypsin, and HD5 indicated the presence of well-differentiated cells able to exert Paneth cell-defensive functions. Although Paneth cell metaplasia has not been described in NEC, this phenomenon has been reported in inflammatory bowel disease (35). Metaplasia can occur through restitution or regeneration of tissue after intestinal mucosal surface loss, either because of resection and inflammation or both (36). However, as our post-NEC stricture patients had not undergone resection during acute NEC, but did show Paneth cell metaplasia, we suggest that inflammation caused Paneth cell metaplasia.

During recovery, lysozyme, trypsin, and sPLA2 were present in intestinal outflow fluid and outflow fluid inhibited bacterial growth in vitro. Similar outcomes were found in in vitro studies performed with human and mouse peptide isolates (37-39). A caveat is that these antibacterial products are not Paneth cell specific. However, the presence of Paneth cells in A-NEC and the presence of these peptides in the ileal outflow fluid imply that Paneth cells in preterm infants are present and at least partially functional by secreting antimicrobial products. Therefore, Paneth cell deficiency, i.e. a lack of Paneth cells, in preterm infants with NEC seems unlikely. However, we cannot exclude that there are abnormalities in Paneth cells that limit their functioning in infants with NEC.

A limitation of this study is that interpretation of our findings is difficult because preterm controls also exhibit signs of inflammation, numbers of age-matched control patients are limited, and collecting material from a healthy control group is not feasible. Nevertheless, our results indicate the presence of Paneth cells in preterm infants with NEC and imply that Paneth cell hyperplasia and metaplasia is most likely caused by inflammation. Subsequently, increased Paneth cell numbers suggests enhanced secretion of active antimicrobial products and might be indicative of an enhanced innate defense response during prolonged inflammation that might contribute to NEC recovery. However, it still remains to be elucidated, which cell signaling and regulatory pathways are involved in these processes to target improvement of therapy and clinical outcome.

Acknowledgment. We thank J. Bouma for excellent technical assistance.

\section{REFERENCES}

1. Paneth J 1888 [About the secreting cells in the small intestinal epithelium] Arch Mikroskop Anat 31:113-191

2. Sandow MJ, Whitehead R 1979 The Paneth cell. Gut 20:420-431

3. Ganz T 2003 Defensins: antimicrobial peptides of innate immunity. Nat Rev Immunol 3:710-720

4. Salzman NH, Underwood MA, Bevins CL 2007 Paneth cells, defensins, and the commensal microbiota: a hypothesis on intimate interplay at the intestinal mucosa. Semin Immunol 19:70-83

5. Ayabe T, Satchell DP, Wilson CL, Parks WC, Selsted ME, Ouellette AJ 2000 Secretion of microbicidal alpha-defensins by intestinal Paneth cells in response to bacteria. Nat Immunol 1:113-118

6. Salzman NH, Ghosh D, Huttner KM, Paterson Y, Bevins CL 2003 Protection against enteric salmonellosis in transgenic mice expressing a human intestinal defensin. Nature 422:522-526

7. Fernandez MI, Regnault B, Mulet C, Tanguy M, Jay P, Sansonetti PJ, Pedron T 2008 Maturation of paneth cells induces the refractory state of newborn mice to Shigella infection. J Immunol 180:4924-4930

8. Wilson CL, Ouellette AJ, Satchell DP, Ayabe T, Lopez-Boado YS, Stratman JL, Hultgren SJ, Matrisian LM, Parks WC 1999 Regulation of intestinal alpha-defensin activation by the metalloproteinase matrilysin in innate host defense. Science 286:113-117

9. Salzman NH, Hung K, Haribhai D, Chu H, Karlsson-Sjoberg J, Amir E, Teggatz P, Barman M, Hayward M, Eastwood D, Stoel M, Zhou Y, Sodergren E, Weinstock GM, Bevins CL, Williams CB, Bos NA 2010 Enteric defensins are essential regulators of intestinal microbial ecology. Nat Immunol 11:76-83

10. Lin PW, Simon PO Jr, Gewirtz AT, Neish AS, Ouellette AJ, Madara JL, Lencer WI 2004 Paneth cell cryptdins act in vitro as apical paracrine regulators of the innate inflammatory response. J Biol Chem 279:19902-19907

11. Lencer WI, Cheung G, Strohmeier GR, Currie MG, Ouellette AJ, Selsted ME, Madara JL 1997 Induction of epithelial chloride secretion by channel-forming cryptdins 2 and 3. Proc Natl Acad Sci U S A 94:8585-8589

12. Erlandsen SL, Parsons JA, Taylor TD 1974 Ultrastructural immunocytochemical localization of lysozyme in the Paneth cells of man. J Histochem Cytochem 22:401-413

13. Klockars M, Reitamo S 1975 Tissue distribution of lysozyme in man. J Histochem Cytochem 23:932-940

14. Kiyohara H, Egami H, Shibata Y, Murata K, Ohshima S, Ogawa M 1992 Light microscopic immunohistochemical analysis of the distribution of group II phospholipase A2 in human digestive organs. J Histochem Cytochem 40:1659-1664

15. Jones DE, Bevins CL 1992 Paneth cells of the human small intestine express an antimicrobial peptide gene. J Biol Chem 267:23216-23225

16. Jones DE, Bevins CL 1993 Defensin-6 mRNA in human Paneth cells: implications for antimicrobial peptides in host defense of the human bowel. FEBS Lett 315:187192

17. Klockars M, Reitamo S, Adinolfi M 1977 Ontogeny of human lysozyme. Distribution in fetal tissues. Biol Neonate 32:243-249 
18. Mallow EB, Harris A, Salzman N, Russell JP, DeBerardinis RJ, Ruchelli E, Bevins CL 1996 Human enteric defensins. Gene structure and developmental expression. J Biol Chem 271:4038-4045

19. Coutinho HB, da Mota HC, Coutinho VB, Robalinho TI, Furtado AF, Walker E, King G, Mahida YR, Sewell HF, Wakelin D 1998 Absence of lysozyme (muramidase) in the intestinal Paneth cells of newborn infants with necrotising enterocolitis. J Clin Pathol 51:512-514

20. Sharma R, Tepas JJ III, Hudak ML, Wludyka PS, Mollitt DL, Garrison RD, Bradshaw JA, Sharma M 2005 Portal venous gas and surgical outcome of neonatal necrotizing enterocolitis. J Pediatr Surg 40:371-376

21. Blakely ML, Lally KP, McDonald S, Brown RL, Barnhart DC, Ricketts RR, Thompson WR, Scherer LR, Klein MD, Letton RW, Chwals WJ, Touloukian RJ, Kurkchubasche AG, Skinner MA, Moss RL, Hilfiker ML 2005 Postoperative outcomes of extremely low birth-weight infants with necrotizing enterocolitis or isolated intestinal perforation: a prospective cohort study by the NICHD Neonatal Research Network. Ann Surg 241:984-989; discussion 989-994

22. Lin PW, Stoll BJ 2006 Necrotising enterocolitis. Lancet 368:1271-1283

23. Lucas A, Cole TJ 1990 Breast milk and neonatal necrotising enterocolitis. Lancet 336:1519-1523

24. Claud EC, Walker WA 2001 Hypothesis: inappropriate colonization of the premature intestine can cause neonatal necrotizing enterocolitis. FASEB J 15:1398-1403

25. Bell MJ, Ternberg JL, Feigin RD, Keating JP, Marshall R, Barton L, Brotherton T 1978 Neonatal necrotizing enterocolitis. Therapeutic decisions based upon clinical staging. Ann Surg 187:1-7

26. Renes IB, Verburg M, Bulsing NP, Ferdinandusse S, Buller HA, Dekker J, Einerhand AW 2002 Protection of the Peyer's patch-associated crypt and villus epithelium against methotrexate-induced damage is based on its distinct regulation of proliferation. J Pathol 198:60-68

27. Schaart MW, Yamanouchi T, van Nispen DJ, Raatgeep RH, van Goudoever JB, de Krijger RR, Tibboel D, Einerhand AW, Renes IB 2006 Does small intestinal atresia affect epithelial protein expression in human newborns? J Pediatr Gastroenterol Nutr 43:576-583
28. Meijerink J, Mandigers C, van de Locht L, Tonnissen E, Goodsaid F, Raemaekers J 2001 A novel method to compensate for different amplification efficiencies between patient DNA samples in quantitative real-time PCR. J Mol Diagn 3:55-61

29. Schaart MW, Schierbeek H, de Bruijn AC, Tibboel D, van Goudoever JB, Renes IB 2006 A novel method to determine small intestinal barrier function in human neonates in vivo. Gut 55:1366-1367

30. Tytgat KM, Klomp LW, Bovelander FJ, Opdam FJ, Van der Wurff A, Einerhand AW, Buller HA, Strous GJ, Dekker J 1995 Preparation of anti-mucin polypeptide antisera to study mucin biosynthesis. Anal Biochem 226:331-341

31. Holman RC, Stoll BJ, Clarke MJ, Glass RI 1997 The epidemiology of necrotizing enterocolitis infant mortality in the United States. Am J Public Health 87:2026-2031

32. Maayan-Metzger A, Itzchak A, Mazkereth R, Kuint J 2004 Necrotizing enterocolitis in full-term infants: case-control study and review of the literature. J Perinatol 24:494-499

33. Sankaran K, Puckett B, Lee DS, Seshia M, Boulton J, Qiu Z, Lee SK 2004 Variations in incidence of necrotizing enterocolitis in Canadian neonatal intensive care units. J Pediatr Gastroenterol Nutr 39:366-372

34. Salzman NH, Polin RA, Harris MC, Ruchelli E, Hebra A, Zirin-Butler S, Jawad A, Martin Porter E, Bevins CL 1998 Enteric defensin expression in necrotizing enterocolitis. Pediatr Res 44:20-26

35. Tanaka M, Saito H, Kusumi T, Fukuda S, Shimoyama T, Sasaki Y, Suto K, Munakata A, Kudo H 2001 Spatial distribution and histogenesis of colorectal Paneth cell metaplasia in idiopathic inflammatory bowel disease. J Gastroenterol Hepatol 16:1353-1359

36. Helmrath MA, Fong JJ, Dekaney CM, Henning SJ 2007 Rapid expansion of intestinal secretory lineages following a massive small bowel resection in mice. Am J Physiol Gastrointest Liver Physiol 292:G215-G222

37. Eisenhauer PB, Harwig SS, Lehrer RI 1992 Cryptdins: antimicrobial defensins of the murine small intestine. Infect Immun 60:3556-3565

38. Ouellette AJ, Hsieh MM, Nosek MT, Cano-Gauci DF, Huttner KM, Buick RN, Selsted ME 1994 Mouse Paneth cell defensins: primary structures and antibacterial activities of numerous cryptdin isoforms. Infect Immun 62:5040-5047

39. Porter EM, van Dam E, Valore EV, Ganz T 1997 Broad-spectrum antimicrobia activity of human intestinal defensin 5. Infect Immun 65:2396-2401 